about by the extensive works undertaken for the improvement of the public health by numerous sanitary authorities throughout the country.

It would be quite out of the question to separate consumptive persons from their families and confine them in isolation hospitals for months or even some years, as may reasonably be done in the case of infectious diseases lasting but a few weeks.

We must trust largely to education of the public in these subjects for the further prevention of consumption, and with that end in view it might be of advantage for you to issue leaflets giving plain advice on the measures to prevent the disease; but probably as much migbt be done in that direction without as with notification, because such leaflets might be distributed to all the medical men in the borough with a request that they would give one to each of their consumptive patients.

\section{SEWER FLUSHING AND VENTILATION.}

IN an important report presented by the Special Purposes and Sanitary Committees to the Metropolitan Board of Works in 1886 , the simultaneous and copious flushing of house-drains by householders on stated days and hours is recommended as one of the most effectual means of flusbing the sewers. Apart from this, I beg to direct your attention to the necessity which I believe exists for the provision of one or more larger flushingvans, and of many more larger automatic flushing tanks, the value of which is daily becoming more and more widely recognized. In Croydon, 40 flushing tanks, each of from 2,000 to 3,000 gallons capacity are in use. In Leicester, where, during 1893 , an epidemic of typhoid occurred, causally related as is believed to inefficient sewer-ventilation and cleansing, the Corporation have been advised to provide at important points on the chief lines of sewers flushing tanks of 2,000 or 3,000 gallons capacity : at the upper ends of each of the district sewers tanks of $r, 000$ gallons capacity : while at the dead end of each branch sewer it is proposed to provide a manhole of 500 gallons capacity, with a flushing penstock or disc-valve enabling it to be filled with water by a hose pipe and utilized as a flushing chamber. The Borough Engineer (Mr. Mawbey) also emphasises the necessity of periodically cleansing the upper surfaces of the large main-sewers, which may be done with a hose pipe.

A practical difficulty in this way of systematic and thorough cleansing of the sewers is, I understand, the present heavy cost of water, and as the matter is one vitally affecting the health and welfare of the Borough, it is to be hoped that some more satisfactory arrangement in this respect may be speedily arrived at.

With regard to the ventilation of sewers, $\mathrm{Mr}$. Mawbey, of Leicester, recommends that instead of wooden poles being used on the highways for telephone and telegraph wires, steel shafts should be adopted having a sectional area about equal to a 9-inch pipe. He points out that in some cases these shafts would an'wer the' threefold purpose of ventilating shaft, lamp column, and telegraph or telephone pole.-(From Dr. Porter's Annual Report, Stockport)

\section{THE INFLUENCE OF RAILWAYS IN THE DISSEMINATION OF CHOLERA.}

By Surgeon-Major J. Lewras, M.D., Officiating Statistical Officer to the Government of India in the Sanitary and Medical Departments.

SURGEON-MAjor LEWTAS, after giving in elaborate detail the evidence on this question in the Annual Report of the Sanitary Commissioner with the Government of India for 1893 , sums up his conclusions as follows:-

"Railways do no doubt frequently carry cases of cholera to a considerable distance, but $I$ have searched in vain for any evidence to show that cholera cases thus transported give rise to localised epidemics, which would not otherwise have occurred in the places to which these cases were conveyed. If railways are a means of disseminating cholera, why are they not constantly carrying it from those endemic centres in which it is always present?

"Before beginning this enquiry, I was inclined to think that railways must promote the epidemic spread of cholera; but after reading the histories of epidemic cholera as it occurs in India, and also in other countries, I have arrived at the following conclusions :-

"x. Railways convey patients suffering from cholera to places which they would not have reached in the days $b=$ fore railways were opened, but such cases do not by themselves determine, or even appreciably influence, the course of the epidemic.

"2. Railways are a great safeguard to those who use them in order to escape from an infected locality ; and as they constitute the quickest means of dispersing a large collection of people from any place in which cholera has appeared, their influence, so far as these people are concerned, is eminently salutary, and the consequent introduction of some cases of cholera to previously non-infected places is dangerous only in so far as the sanitation of these may be defective. Seeing that pilgrims return to hundreds of thousands of villages and towns without their return being followed by outbreaks of cholera in more than hundreds of them it is reasonable to presume that the outbreaks in the latter are due to some causes peculiar to them and not common to the thousands that escape: in other words, that the 'fault,' whether it be defective sanitation or something else, is not proper to the pilgrims. This statement is based not only 
upon the records of Indian experience, but also upon those of the European epidemics of 1884 and 1885. In a supplement to the 15 th Annual Report of the Local Government Board, page ro7, the following passages occur: 'The experience of cholera in England justifies a belief that the presence of imported cases of the disease at various spots in the country will not be capable of causing much injury to the population, if the places receiving infection have had the advantage of proper sanitary administration.' Again, 'Cholera in England shows itself so little contagious, that, if reasonable care be taken where it is present, there is almost no risk that it will spread to persons who nurse and otherwise closely attend upon the sick.' One more extract from the same report: "Thus, when a case of cholera is imported into any place, the disease is not likely to spread unless in proportion as it finds, locally open to it, certain facilities for spreading by indirect infection.' These and other references in this paper to European and American experience are not, I venture to think, irrelevant, because they show that those who have had especially favourable opportunities for observing cholera there, have arrived at conclusions which agree with our experience of the disease in India.

"If railways were a means of disseminating cholera, they would obviously convey it in every direction indifferently. But, in the Bengal Presidency, "the direction of an epidemic is always upwards,' i.e., towards the North-West Frontier. 'Such a thing as an epidemic moving downwards is absolutely unknown' (Cholera: By SurgeonGeneral Cuningham, page $2 \mathrm{I}$ ). This fact alone would suffice to show that the influence of railways upon the distribution of cholera is inappreciable."

\section{MALARIA IN NEW JERSEY.}

DR. J. C. SMOCK, the State Geologist for New Jersey, U.S.A., has summarised the facts as to the origin and means of preventing malaria in New Jersey under the following heads:-

x. Malarial fevers prevail over that part of the State which lies north of the terminal moraine, wherever $r_{i}$ the conditions are favourable to it.

2. There is a remarkable absence of malaria in the country south of the terminal moraine, excepting localities and districts of limited extent, where aggravated conditions of its determination exist.

3. The existence of malaria is not necessarily due to a geologic formation, but to a sub-surface condition, common in the country which is north of the terminal moraine, and covered more or less by glacial drift.

4. The element of imperfect or disturbed underdrainage is a more potent condition in determining malaria than any other.

5. The thorough under-draining of a district or tract is the most practicable and most effective means in order to amelioration and protection.
6. The distance to which the malarial poison may be carried by winds or air-currents is com. paratively short, and not over hills and mountains miles away, as often popularly stated.

7. Belts of forests, and even hedges, tend to arrest this conveyance of malaria by winds. One instance was cited where, in the northern part of the State, a hedge is reported to have prevented malaria. The hedge was cut down and the whole family was taken down sick with malarial disease. The occurrence of malaria or its distribution areally in New Jersey seems to be explained by these conditions of sub-surface drainage and the essential factors of heat, moisture, and dead vegetation, and not by wind-transmission, otherwise there would be greater uniformity in the occurrence, instead of the irregular distribution. We have here a fever-stricken locality, and there an area free from it.

The writer cited the testimony of several physicians of the northern part of the State as opposed to any wide diffusion by winds. The wet tracts of the Upper Passaic Valley are reputed to be the source of all the malaria in all the northeast part of the State, which has been designated as a pestilential nest of malaria ; but malaria does not occur on all of the adjacent slopes of the Archæan hills and the trap-rock ridges, as would be expected if the prevailing winds carried it any great distance. The possibility is suggested that the many tracts of woodland serve as barriers to arrest the progress upon these higher surrounding hills. That malaria may be carried short distances would seem evident along the valley of the Passaic at Belleville, according to Dr. Skinner, while the physicians of Montclair and the Oranges, from whom Dr. Smock quoted at some length, refer their cases of malaria to local causes, and not to any possible wave of it sweeping over the Orange Mountains. Dr. Wolfe, of Chatham, limits the distance of such transmission to one-half or one mile.

Referring to the Great Meadows of the Pequest Valley, in Warren county, the testimony of intelligent laymen there resident led the writer to believe that there is no malaria there. Formerly this valley was "full of it ;" as one said, "Nearly every one had the shakes." The beneficial effects are attributed to the lowering of the bed of the Pequest river and the more rapid delivery of its waters. Where formerly were wide-spread inundated lands and a sluggish stream with scarcely a perceptible current, there are to-day productive gardens and a swift current. The possibility of future outbreaks was suggested by the writer, until the whole tract has its ground-water lowered sufficiently to make a well-drained soil and sub-soil, as well as a thorough surface system of drainage.

Dr. J. Priestrey, late M.O.H. of Leicester, has been appointed M.O.H. of the Parish of Lambeth. 